\title{
Agile Risk Management as a Solution to the Failure of Kenyan Public Projects
}

\author{
Amecha Caroline Sikweya, Peter Njeru Njue \\ Department of Construction Management and Quantity Surveying, University of Nairobi, Nairobi, Kenya
}

Email address:

amechacaroline@gmail.com (A. C. Sikweya),pnnjeru@uonbi.ac.ke (P. N. Njue)

\section{To cite this article:}

Amecha Caroline Sikweya, Peter Njeru Njue. Agile Risk Management as a Solution to the Failure of Kenyan Public Projects. American Journal of Engineering and Technology Management. Vol. 6, No. 3, 2021, pp. 35-40. doi: 10.11648/j.ajetm.20210603.12

Received: May 15, 2021; Accepted: June 1, 2021; Published: June 7, 2021

\begin{abstract}
Risk management is key in determining the success of a project. Despite adoption of risk management by the public sector in Kenya, research has shown that up to $79.2 \%$ of the construction projects still fail whether in terms of experiencing delays, cost overruns or failure to meet the expected quality. The main aim of this study was to establish whether Agile Risk Management principles present a practical improvement to the predominant practice of risk management in the Kenyan public sector. Data was collected from a team of Architects, Engineers and Quantity Surveyors in the State Department of Public Works, Nairobi, using questionnaires and an interview. Results obtained showed that risks are directly related to the causes of failure of these Kenyan public projects and therefore improving risk management practices will promote the success of these projects. It was also evident from the study that the predominant approach to risk management in Kenya was Traditional Risk Management. The Agile Risk Management principles are hardly implemented in Kenya owing to the fact that professionals are not aware of this approach. Upon further analysis, this study established that the adoption of some Agile Risk Management principles is indeed a solution to the failure of Kenyan public projects as it presents a practical improvement to the predominant risk management practices. This study brings to light the need to closely examine the risk management practices in Kenya generally in both the public and private sectors. Another implication of this study is that it highlights the need of professional bodies and other relevant authorities to create more awareness on this and other approaches to risk management among their members.
\end{abstract}

Keywords: Risk, Traditional Risk Management, Agile Risk Management

\section{Introduction}

Construction risk management has over the years shown to be an important tool in promoting the success of construction projects [7]. Risk management entails condensing, absorbing and transferring risks while making sure to exploit the full potential of opportunities. Stakeholders of the construction industry have been employing risk management whether using formal procedures or using informal approaches [11]. When carried out effectively, risk management is a key ingredient in promoting and/ or ensuring the success of a project [13].

A project's success or failure can be determined by measuring its performance against the objectives of time, money, scope and quality, which are essentially the Key Performance Indicators (KPIs) [14]. An examination of Kenyan public projects against these KPIs reveals a very low success rate. Research done to investigate the performance of public projects showed only a $20.8 \%$ success rate, $79.2 \%$ failing in one aspect or another [15]. Many of the construction projects initiated by the Kenyan government either stalled or lay idle, went beyond the budgetary allocation or took longer than was planned.

Research has shown that risk management and the performance of a project are directly related. Therefore, it can be deduced that a project team that is keen on using effective and efficient risk management practices, is relatively at a better position of implementing a project in time, within the triple constraint of money, time, and scope, and to the intended quality than one which does not. Bearing this in mind, the rate of failure of these public projects is a clear indication that the current risk management practices employed by the public sector are either ineffective and/ or inefficient [1].

In order to deal with the inefficiencies and misgivings of the traditional approach of risk management, various 
approaches have been adopted within the construction industry generally. One such approach is Agile Risk Management [21]. This approach operates by breaking down the project into small manageable pieces (iterations/ scrums/ sprints) to be finished in small sessions, say two to six weeks [16]. The main benefit of agility as an approach to general project management (including risk management) is that it promotes the success of a project by improving the ability to react to issues (risks) as they come up in the course of the project. Simply put, the agile approach minimizes the overall risk to the projects. The efficiency of this approach was made evident by projects such as the Centrus Energy Corporation RD\&D Project [19].

This paper presents an investigation of how the implementation of this Agile approach to risk management can serve as a solution to the failing Kenyan public projects. This proposition is founded on the outcome of the three following objectives: 1 . To establish the relationship between causes of failure of past Kenyan public projects and common risks associated with the public sector construction projects, 2. To determine the current predominant approaches to risk management in the Kenyan public sector and 3. To determine whether agile risk management is an improvement to the management of the identified common risks facing the public sector construction projects.

\section{Risk Management in the Kenyan Public Sector}

Studies have shown that the Kenyan government employs risk management in the running of the construction projects [13]. The predominant approach is Traditional Risk Management. Traditional Risk management is a structured and continuous process of managing risks. In the case of construction projects, it is carried throughout the entire project, from the first phase to the last in a continuous manner. It is also considered the waterfall approach, where there are multiple planned stages of execution following a sequential manner [4]. This process can be illustrated as:

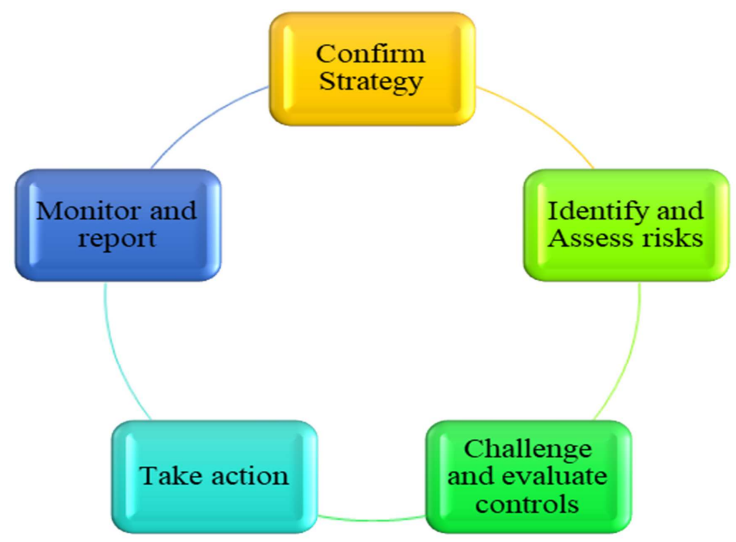

Figure 1. Cyclic Representation of Traditional Risk Management. Source, Authors [1].

This approach has proved to be problematic within the
Kenyan public sector given the performance of the constructed projects. A lot of the projects initiated by the Kenyan government have failed to fulfil the objectives for which they were started with respect to time, cost, quality and scope (KPIs) and can thus be considered failed [6]. For instance, in 2009, there were several projects under the 22 billion programme that were planned. Some of these projects are either stalled, lie idle or have become 'white elephants'. Among the failed construction projects in this programme, is the failed attempt to build a fertilizer plant in Mombasa and failed attempts to build a maize cob processing factory in Eldoret. Most Narok projects were abandoned before the end of 2012, with the contractors leaving the site and this was blamed on poor monitoring. The stalled or incomplete projects include: Construction of Jua Kali sheds in Nakuru, Rongai, Molo and Kuresoi (allocated 6 million each) and the Wakulima Hawkers' business complex in Nakuru (allocated 40 million) which lies incomplete because the contractors were not paid. The free air market that was planned in the programme was completed but could not be occupied by 2014 because the contractors were not settled [18]. Quite recent (2019), is the Kimwarer 21 billion dam scandal, where large sums of money had allegedly been allocated to the construction of dams but no construction was done. The President of the Republic of Kenya at the time of this Kimwarer project had to scrape off the deal in September, 2019 as it was attached to a scandal that saw eight arrested and questioned. This project was meant to serve the citizens living around Kimwarer and even beyond but it has been rendered failed following the alleged fraudulent misappropriation of funds. The Standard Gauge railway, another mega project of the government, is reported to have gone beyond its budgetary allocation, having cost overruns of up to 2.8 Billion Kenyan Shillings [1].

An examination of the traditional approach to risk management has shown that it has a number of challenges which could explain this poor performance of projects [17]. Ineffective execution of risk management in the traditional approach could be as a result of lack of formalized procedures, including risk identification, analysis and control [10]. Mere quotation of contingencies or float is insufficient. In the traditional approach there is no standard procedure to follow, it is adopted as it well suits the organization. Another challenge that could render this approach ineffective is the absence of a follow up system in the risk management process from stage to stage of the project life cycle [1]. Most of the users of the traditional approach confine the process to the planning phase and thus may fail to deal with risks that had not been foreseen but came up in later stages. Due to the sequential nature of the waterfall method, there is not much room for continuous development or effective change management [1]. Furthermore, the approach alludes an absence of interaction among the various parties including the clients, contractors, insurers and suppliers [1].

All the above shortcomings can explain why this approach as implemented by the Kenyan public sector is inadequate. 


\section{Agile Risk Management}

Agile Risk Management as an approach to risk management is a result of the document dubbed the 'Agile Manifesto' [9]. This manifesto was drafted, almost unintentionally, by a group of seventeen, who thereafter called themselves "The Agile Alliance". The seventeen were independent thinkers involved in software development and were contenders to some level [9]. The Agile Manifesto can be considered an anti- methodology. The authors sought to redefine 'methodology' by aiming to restore balance, embrace modelling and maintenance of documents (but not in hundreds and thousands of pages that are hardly upheld and seldom used) [1]. They also embraced planning but acknowledged its limits in an environment that is turbulent. The main objective was to uncover improved methods of developing software by actualizing these methods and abetting others to do it. They had four core values: Individuals and interactions over tools and processes, working software over comprehensive documentation, customer collaboration over contract negotiation and responding to change over following a plan. These values are further broken down into twelve principles which act as a guideline in the adoption of this approach [9].

Agile Risk Management was eventually picked up in the construction industry. Every team adopted the most practical principles with respect to the project they are handling. Therefore, each principle or value in the Agile Manifesto is given a construction translation [2]. The figure below shows examples of the translations:

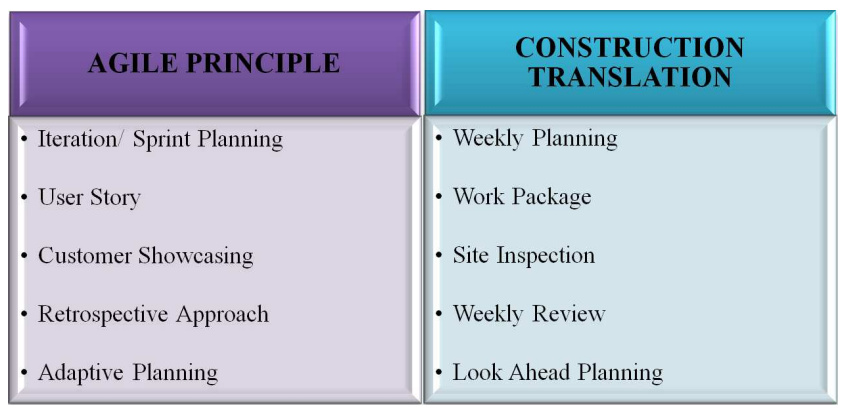

Figure 2. Construction Translation of Agile Principles. Source, Authors.

The Agile process generally has an advantage over the waterfall/ traditional process since it is more responsive to change. Agility in risk management will promote a higher visibility of the risk, support informed decision making and ensure shared ownership and responsibility in relation to the risk [1]. Owing to this, agile principles help in minimizing time between when a risk is detected and when it is corrected [5]. In this approach, the participants may be able to tell what exactly it is that they are doing. However, it may not occur to them the impact of what they are doing to the overall project risk and their contribution to its management [1].

Unlike traditional risk management, agile risk management has set formal procedures that allow for continuity of the risk management throughout the different phases [12]. Agile methods call for frequent stand up meetings that will, in the case of RM, allow for frequent discussions of risks and how they were handled. Due to this frequency, these discussions will be consistent, throughout the project duration [1].

Lack of interaction between parties was an identified challenge of the traditional approach. Agile risk management deals with this by requiring regular meetings for each iteration while including all key players [1]. Different authors discussing the traditional approach bestow risk management responsibilities on various parties. Some the client, some the contractor, while others to the client, consultants and contractors collectively. Agile risk management, however, puts all these parties together, with one of the main values being individuals and interactions over processes and tools. This promotes involvement of all parties [1].

A primary factor leading to failure of TRM is the poor maintenance of information [3]. Agile risk management calls for documentation of necessary information throughout from iteration to iteration. It is a requirement of this approach that the risk reports should be done for each iteration and tabled during the stand-up meetings. In both approaches, risks are recorded in a risk register but the advantage that Agility has over the traditional approach is that in the former, the visibility of such artefacts must be maintained encouraging risk visibility [1].

\section{Adoption of Agile Risk Management in Construction: Centrus Energy Corporation}

The Centrus Energy Corporation is a supplier of nuclear fuel and other services relating to the nuclear power industry. Between the year 2012 and 2014 they carried out a research, design and development (RD\&D) to assert the readiness of the American Centrifuge to the next generation US uranium technology [19]. This involved constructing, installing, operating and testing a commercial plant support system. They completed RD\&D in time and within budget. As in any typical large project, Centrus faced challenges including: Having a fixed time frame with specific milestones that are set up by the customer, having a limited funding in terms of its availability and usability period, and the environment under which the project was executed was highly regulated, in this case by Nuclear Regulatory Commission (NRC) and the Department of Energy [19].

The traditional and predominant methods of contracting and construction methods could not facilitate their schedule or funding profiles. Examples of the traditional methods include having firm fixed prices and purely chronological hand-offs between tasks. Their main aim of adopting agile methods was to complete construction safely, on time and within budget [1]. However, there was no formal discussion or decision to use the agile approach rather they implemented the principles without necessarily labelling it; Agile approach.

The RD\&D project adopted the principles of Agility in various ways. 
For instance, the first three principles of the Agile Manifesto are about prioritizing client satisfaction through early and continuous delivery of valuable software and having the working software as the primary measure of progress. In construction, this translates to having an early delivery of functional systems into test and operation. In the RD\&D project, they replaced the normal sequential construction with having components, subsystems, and systems and integrated testing [1]. Upon achieving a functional system, it was delivered to the customer as soon as practically possible to avoid having a single massive project turnover [8].

The fourth principle is to welcome changing requirements however late they come in the development. When it comes to construction, this may be difficult to translate since cost increases exponentially as the project moves into later phases [1]. In RD\&D, they developed an integrated team involving all stakeholders in the review process to ensure the end user and other stakeholders' input was included in the design of the system. They implemented the very late changes while minimizing them to critical needs. This means that changes were only done when they were very critical and important [19].

The next two principles in the Agile Manifesto are about having a close, daily cooperation between business people and developers and having face to face conversations as the best method of communication. The construction translation of that, was to have close cooperation and a team approach rather than adversarial approach. It would also mean holding integrated meetings to share information rather than only electronic data sharing which include reports, emails and schedules [1]. RD\&D developed an integrated team from the first day, with the end user embedded in the design, construction and testing process. The aim of this was to ensure the end result was a functional system that meets the user's needs [1]. They held progress and status meetings used to identify work that needed to be done and support that was deemed necessary while removing barriers. So as to overcome the challenge of distance, they had personnel at the designer's office full time. This was aimed at improving communication [19].

The seventh and eighth principles are to build the project around motivated individuals and give the individuals the environment and support they need while trusting them to get the job done. In construction, this would mean to keep the team motivated and ensure they have shared goals and objectives. This is critical to the project's success. Individual construction is also encouraged and the improvements are based on individual ideas as implemented. The team is also to be provided with a support system to optimize their work [1]. Centrus in their RD\&D project, fostered the team environment with ongoing attempts to maintain a high level of employee morale, vision and goals. Milestone progress was communicated to all stakeholders effectively. The work systems were designed to allow the field workers to be very productive in their efforts to eliminate barriers and reduce delays. The key focus of the project team was the productive hours [19].

Sustainable development by maintaining a constant pace and having self-organizing teams are the next principles as dictated by the Agile Manifesto [9]. The construction translation is to schedule and level resources, so as to maintain a trained, experienced workforce, with project and site specific knowledge preferred to maximize productivity and quality in construction. RD\&D did not fully implement the constant pace principle. They had tight deadlines that did not permit a steady state flow as in software development and maintenance, They used significant compensated overtime to complete the project on schedule. All the labour resources provided by multiple union contractors worked as part of Centrus directed teams. In order to reduce the overall project delays, crews were kept productive even when individual tasks were delayed or waiting on materials or design inputs [8].

The Agile manifesto calls for continuous attention to technical excellence and good designs as well as simplicity. This, in construction, would mean better designs, drawings, work packages and specifications [9]. This will promote fewer delays in the field work and implementation. Clear and simple designs cause less questions from the field during the implementation. Simplicity provides the user with the functionality needed. The RD\&D project provided the best design and work packages. There was a forward based technical support team to answer any questions arising from the design and make any clarification as required. The project was scoped in such a way to provide the needed functionality and system redundancy [19]. A lot of effort was made to simplify designs to reduce both the initial costs and the life cycle costs. The scope items were challenged by the management prior to inclusion in the project [1].

The last principle of the Agile manifesto is that at regular intervals, the team reflects on how to become more effective, the tunes and adjusts behaviours accordingly [9]. Therefore, for construction projects, the root causes of issues, delays or problems are identified and any problems fixed. Improvement of ideas is encouraged and all stakeholders seek it. For RD\&D, the lessons learned were a specific topic done during every weekly progress meeting. Issues highlighted included how to improve, how to eliminate barriers and how to enhance safety, speed and strength [19].

\section{Suitability of Agile Risk Management in Running Kenyan Public Projects}

As seen in the previous section, Agile Risk Management provided an excellent solution for the Centrus Project. However, Agile Risk Management may not be suitable for all projects. As a general guideline, the Agile Approach is most suitable for projects operating in a turbulent environment [1]. The characteristics of the environment that surrounded the RD\&D project include: tight time schedule, limited availability and usability of funds and high regulatory measures [9]. Some Kenyan planned or currently ongoing 
public projects have a similar environment. The LAPSSET is one such project. It is a 2 trillion Lamu Port-South SudanEthiopia-Transport Corridor project. It has important components including the Lamu port, Lamu-Ethiopia-South Sudan superhighway, Lamu-Juba-Addis Ababa railway line, an oil refinery and a 2,240 km oil pipeline connecting oil fields in South Sudan to the refinery at the Lamu Port. Another project in a similarly turbulent environment is the Standard gauge railway, launched on November 28, 2013. This project is currently ongoing, with its first phase complete. Other examples are the Greenfield Terminal, (55.6 billion) which was completed in 2017, the Dongo Kundu Free Port, the Konza Technology City and the Affordable housing projects [20]. Therefore, adoption of the agile approach in risk management may work to the benefit of these and future projects [1].

\section{Adoption of Agile Risk Management to Kenyan Public Projects}

This section explores how practical some Agile Risk Management principles are in the Kenyan context. Adopting risk management involves weighing each principle against how practical it is and how much of an improvement to the traditional practices it gives [1]. A study was done among Architects, Engineers and Quantity Surveyors working in the Kenyan public sector. The professional's general perspective was that the current predominant practices (being traditional risk management) work but could use some improvement, hence justifying the need for adoption of new practices to improve them [1]. The team (94\% of them) had neither heard of Agile risk management nor did they know how it works. The principles that were considered improvements by the vast majority included: Continuous improvement of the final product by fixing flaws and dealing with risks phase by phase, viewing risks by breaking down the project into smaller manageable parts to be completed in sessions and lastly, the collaboration of the whole project team in the risk management process. Further, on examining if ARM would be practical in the context of Kenyan public projects, up to $64 \%$ (which is above average) considered the principles very practical [1].

\section{Conclusions}

Adoption of Agile risk management has proved to be a practical improvement to the traditional practices of managing risks.

The principles, when adopted gradually and given the appropriate construction translation, in accordance to the respective projects, present a solution to the failing projects. From the study, we can deduce the following:

There is a direct relationship between risks facing the public projects and the factors causing their failure. Improving the risk management practices will promote the probability of success of said projects. Therefore, Agile risk management, having shown to be a better approach to managing risks, promises a solution to the failure of Kenyan public projects.

Professional bodies and other relevant authorities should create more awareness around Agile Risk Management and other approaches to Risk Management, to increase its familiarity among professionals.

\section{References}

[1] Amecha, C. S. (2020). Agile Risk Management as a Solution to the Failure of Kenyan Public Projects. Nairobi: University of Nairobi.

[2] Chris, K. (2009, November 2). An Agile Construction Project. Retrieved from Wordpress: wordpress.com

[3] Chapman, D. R. (2018, December). Ineffective Risk Management and the Collapse of Carillion. PM World Journal, VII.

[4] Cliath, O. C. (2015). Introduction to Risk Management (Theory \& Practice). Dublin: Dublin City University.

[5] Daneshgari, P., \& Wilson, M. (2006). The Profitability of Agile Construction. Parviz.

[6] Faruq, O. (2013). Feasibility Study and Detail Design. SSWRDSP \& PSSWRSP of LGED; Bets Consultants Limited.

[7] Gajewska, E., \& Ropel, M. (2011). Risk Management Practices in a Construction Project. Sweden: Chalmers University of Technology.

[8] Gitau, L. M. (2015). The Effects of Risk Management at Planning Phase on Performance of Construction Projects in Rwanda. University of Nairobi. Nairobi: University of Nairobi.

[9] Highsmith, J. (2001). The Agile Manifesto. Manifesto for Agile Software Development: agilemanifesto.org

[10] Liu, J., Li, B., Lin, B., \& Nguyen, V. (2007, November 3). Key Issues and Challenges of Risk Management and Insurance in China's Construction Industry. Emerald Insight.

[11] March, C. (2017). Construction Management Theory and Practice. New york: Routledge.

[12] Moran, A. (2016). Risk Management in Agile Projects from m.isaca.org

[13] Musau, P. M., \& Kirui, D. (2018). International Academic Journals of Information Science and Project Management. Project Management Practices and Implementation of Government Projects in Kenya, Case of Machakos County, 58-79.

[14] Mwangi, H. M., \& Ngugi, D. (2018). Risk Management Practices and Performance of Construction Projects in Nairobi City County Government, Kenya. International Academic Journal of Information Sciences and Project Management, $111-136$.

[15] Nyika, D. (2012). An Analysis of Causes of Failure in the Implementation of Projects in Kenya. The University of Nairobi, Department of Real Estate and Construction Management. Nairobi: University of Nairobi. 
[16] Rouse, M. (2018, January). whatis.com. Retrieved October 25, 2019, from Agile Project Management: searchcio.techtarget.com

[17] Smith, N. J. (1999). Managing Risks in Construction projects. Iowa State Press: Blackwell Publishers.

[18] Steve Mkawale, K. K. (2014, May 4). Years Later, Ambitious County Projects Remain Incomplete. Standard Digital: standardmedia.co.ke.
[19] Stracusser, G. (2015). Agile Project Management Concepts Applied to Construction and other Non- IT Fields. Project Management Institute. Orlando.

[20] Thuita, P. (2016, January 23). Inventory of major construction projects in Kenya.

[21] White, K. R. (2008). Agile Project Management; A Mandate for the Changing Business Environment. Denver: Project Management Issues. 